\title{
Options for Reducing Transport Fuel Consumption and Greenhouse Emissions for Sydney
}

\author{
Dr Garry Glazebrook, Senior Lecturer, University of Technology, Sydney \\ Peter Rickwood, PhD Student, University of Technology, Sydney
}

\begin{abstract}
This paper examines the potential implications of peak oil and global warming for urban passenger transport in Sydney. After analysing patterns of transport fuel consumption and greenhouse emissions for Sydney, the paper examines potential mitigation strategies, including options for minimising travel demand, reducing oil and $\mathrm{CO}_{2}$ intensiveness, and shifting travel to more sustainable modes. It then proposes some plausible future scenarios for oil supplies and climate change, and examines their implications for urban transport in Sydney. The paper concludes that policy options for addressing these scenarios exist but will need to be accelerated to avoid the risk of major disruptions to our lifestyles and economy.
\end{abstract}

\section{Introduction}

Since the release of the movie "An Inconvenient Truth" in 2006 and the Stern Report (HM Treasury, 2006), global awareness of climate change has grown rapidly. There is now widespread recognition of the threat from global warming, and the consequent need to curtail $\mathrm{CO}_{2}$ and other greenhouse gas emissions. As Hansen et al. (2007) note ( $p$ 2308):

"Our conclusion that global temperature is nearing the level of dangerous climate effects implies that little time remains to achieve the international cooperation needed to avoid widespread undesirable consequences. CO2 emissions are the critical issue, because a substantial fraction of these emissions remain in the atmosphere "forever", for practical purposes... The task is to achieve a transition to clean carbon-free energy sources, which are essential on the long run, without pushing the climate system beyond a level where disastrous irreversible effects become inevitable".

Somewhat less well recognised is the threat to our current way of life from the peaking of oil (and gas) production. However books such as "Twilight in the Desert" (Simmons, 2005) and "Addicted to Oil" (Rutledge, 2005) have highlighted the current dependence of the world on cheap oil, and the potential impacts when global oil production peaks at the same time as oil consumption in countries such as China is rising rapidly. It is worth remembering that peak oil production was reached in the lower 48 states of the USA in 1970, in Texas in 1972, in the whole of North America (including Canada and Alaska) in 1985, in the UK in 1999 and in Norway in 2001. Although no one can be sure until a few years after it happens, peak oil is likely to be very close (Table1).

Table 1: Forecasts of Global Peak Oil Production

\begin{tabular}{|l|l|l|l|}
\hline \multicolumn{1}{|c|}{ Already Happened } & \multicolumn{1}{|c|}{$2007-2010$} & \multicolumn{1}{|c|}{$2010-2020$} & \multicolumn{1}{|c|}{ After 2020 } \\
\hline 2005 Deffeyes (US) & 2010 Skrebowski (UK) & After 2010 (World Energy & CERA (US) \\
2006-7 Bakhtiari (Iran) & 2010 Campbell (Ireland) & Council) & ElA (US) \\
$2006-7$ Simmons (US) & $\begin{array}{l}\text { Before 2010 Goodstein } \\
\text { 2012 Weng (China) } \\
\end{array}$ & (US) & \\
\hline
\end{tabular}

Source: Bezdek (2007)

Furthermore history shows that oil production in a region can fall sharply after the peak, typically by 2$6 \%$ p.a. (Bezdek, 2007). If this happens at a global scale, there will be no time to make the necessary adjustments to world energy systems, especially transport systems, without major economic and social disruptions. Oil-intensive industries and countries which are dependant on imported oil are likely to be affected by price rises and / or physical shortages. Foremost among the vulnerable are road-based transport and those cities most dependent on cars for their mobility.

It is the co-incidence of these two great challenges - climate change and peak oil - which creates a major adjustment challenge for the world. This paper explores some of the options for addressing this challenge for the specific case of urban passenger transport in Sydney. The next Section sets out a brief background to the threats from climate change and peak oil; Section 3 examines transport fuel consumption and greenhouse gas emissions in Sydney; while Section 4 identifies a range of strategies which could be adopted to reduce these. Section 5 explores some future scenarios for peak oil and climate change, while Section 6 concludes by discussing their implications and whether current responses will be sufficient to meet the challenge. 


\section{$2 \quad$ Climate Change and Peak Oil}

In the last two years the world has discovered that we face a major climate threat from global warming, and that this is highly likely due to the effects of burning fossil fuels and other human - induced effects (IPCC, 2007). Already, many countries including the European Union and Japan, as well as individual States such as California and New York and an increasing number of cities, have set targets of $60 \%$ or greater reductions in Greenhouse gas emissions by 2050. There is now widespread expectation that there will be changes in US policy following the next presidential election, due in November 2008, which could then put pressure on China and India to limit their emissions. Statements by the major parties in Australia indicate we are set to join a global carbon trading regime by $2010-2012$. This is just as well, as prominent scientists such as James Hansen warn that the world's climate system runs a risk of "run-away" warming once $\mathrm{CO}_{2} \mathrm{e}$ exceeds $450 \mathrm{ppm}$ (Hansen et. al, 2007). On current trends (430 ppm $\mathrm{CO}_{2} \mathrm{e}$ in 2006, rising at 3 ppm p.a.), this could happen within seven years.

Although a few commentators such as Newman and Kenworthy (1999) have warned of oil and energy dependency for some time, it is only recently that awareness of a similar timeframe for action on oil is also emerging. Irrespective of when the peak finally occurs, it is extremely unlikely that we will return to the golden age between 1930 and 1970 , when oil was US $\$ 10-15$ a barrel in 2005 SUS (Figure 1). Oil recently passed US $\$ 80$ a barrel for the first time.

Figure 1: Real World Crude Oil Prices: 1861-2005

US dollars per barrel

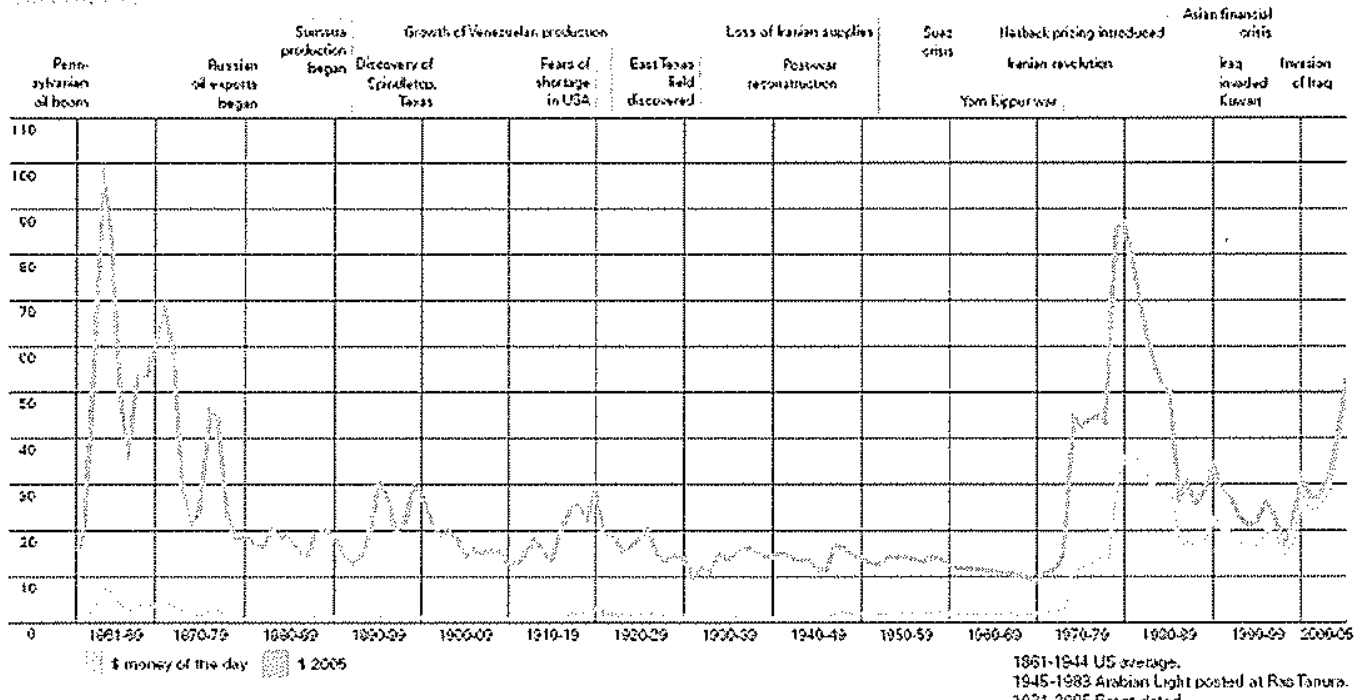

Source: Dunlop (2007)

To appreciate the significance of peak oil, we need to be reminded that:

- $80-95 \%$ of all transport is fuelled by oil products, depending on the country

- All petrochemicals and $99 \%$ of all lubrication is done with oil products

- $95 \%$ of all goods in the shops get there using oil

- $99 \%$ of our food involves oil or gas for fertilisers, agrochemicals, tilling, cultivation and transport

- Oil production has exceeded new oil discovery ever since the early 1980's

- Oil is our most important energy source accounts for $36.4 \%$ of all primary energy used by humans. (Dunlop, 2007).

Consequently, any disruption to either oil supplies or prices could cause major impacts (Newman, 2005). Previous price hikes in 1974, 1979, 1991 and 2001 were followed by recessions. However, the situation now is more critical, both because peak oil is closer, and because of problems with alternatives. For example gas supplies are also becoming a problem in the United States (Simmons 2007); alternative liquid fuel substitutes such as coal - to - liquids and Canadian tar sands have higher GHG emissions per unit energy than oil, and very high capital investment costs (Bezdek, 2007); and there are serious questions as to the viability of large-scale use of biofuels to replace petroleum (Bezdek, 2007) As a consequence, there is growing recognition in the United States and elsewhere of the critical nature of oil, and more generally, energy security (Hirsh et. al., 2005; International Energy Agency, 2005; Standing Committee on Rural and Regional Affairs and Transport, 2007). 


\section{$3 \quad$ Transport Fuel Consumption and Greenhouse Emissions for Sydney}

From the perspective of climate change, the key variable of interest is greenhouse gas emissions. However from a peak oil perspective, the most critical variable of interest is oil consumption. While both are important they are not synonymous, since, for example, a switch to wind or other renewable sources for electricity, or an increase in ethanol or bio-diesel as a component of transport fuels, will alter relationships between energy use, greenhouse gas emissions and oil consumption.

Comprehensive data on all aspects of this issue is not currently available. However the following discussions summarises some of the key information available together with some recent research on relationships between some of the variables of interest for Sydney. In global terms, Australian cities have much lower per capita car use, transport energy consumption and $\mathrm{CO}_{2}$ emissions than the United States, but significantly higher than cities in Europe or Asia (Table 2).

Table 2: Relative Energy, Fuel and CO2 Emissions for Various Cities (1990)

\begin{tabular}{|l|c|c|c|c|c|}
\hline Country / Region & US (a) & $\begin{array}{c}\text { Australia } \\
\text { (b) }\end{array}$ & $\begin{array}{c}\text { Europe } \\
\text { (c) }\end{array}$ & $\begin{array}{c}\text { Wealthy } \\
\text { Asian (d) }\end{array}$ & $\begin{array}{c}\text { Developing } \\
\text { Asian (e) }\end{array}$ \\
\hline Car-km per person & $166 \%$ & $100 \%$ & $69 \%$ & $23 \%$ & $28 \%$ \\
\hline Private Transport energy Cons / capita & $167 \%$ & $100 \%$ & $53 \%$ & $21 \%$ & $20 \%$ \\
\hline Transport $\mathrm{CO}_{2} /$ capita & $163 \%$ & $100 \%$ & $68 \%$ & $42 \%$ & $30 \%$ \\
\hline
\end{tabular}

(a) Houston, Phoenix, Detroit, Denver, Los Angeles, San Francisco, Boston, Washington, Chicago, New York

(b) Perth, Brisbane, Melbourne, Adelaide, Sydney

(c) Hamburg, Frankfurt, Zurich, Stockholm, Brussels, Paris, London, Munich, Copenhagen, Vienna, Amsterdam

(d) Tokyo, Singapore, Hong Kong

(d) Bangkok, Jakarta, Kuala Lumpur, Manila, Surabaya, Seoul, Beijing

Source: Newman, $P$ (2005). Author has converted original data to percentages relative to that for Australian cities.

Sydney is somewhat better placed than other Australian cities in this respect, with lower per capita transport energy consumption than other capitals (Table 3).

Table 3: Transportation Energy Consumption for Australian Capitals (1990) (MJ/capita)

\begin{tabular}{|l|r|r|r|r|r|r|}
\hline City & \multicolumn{1}{|c|}{ Sydney } & Melbourne & Brisbane & \multicolumn{1}{|c|}{ Perth } & \multicolumn{1}{c|}{ Adelaide } & Canberra \\
\hline Private & 33,972 & 38,140 & 38,361 & 40,544 & 36,143 & 44,032 \\
\hline Public & 1,102 & 749 & 916 & 851 & 959 & 962 \\
\hline Total & 35,074 & 38,889 & 39,277 & 41,395 & 37,102 & 44,994 \\
\hline Index & $100 \%$ & $111 \%$ & $112 \%$ & $118 \%$ & $106 \%$ & $128 \%$ \\
\hline
\end{tabular}

Source: Newman and Kenworthy (1999), Table 3.2

Less well-known is the fact that average per capita weekday travel by car in Sydney is also $15 \%$ less than for Newcastle and Wollongong (Figure 2).

Figure 2: Per Capita Weekday Travel Patterns in Sydney, Newcastle and Wollongong

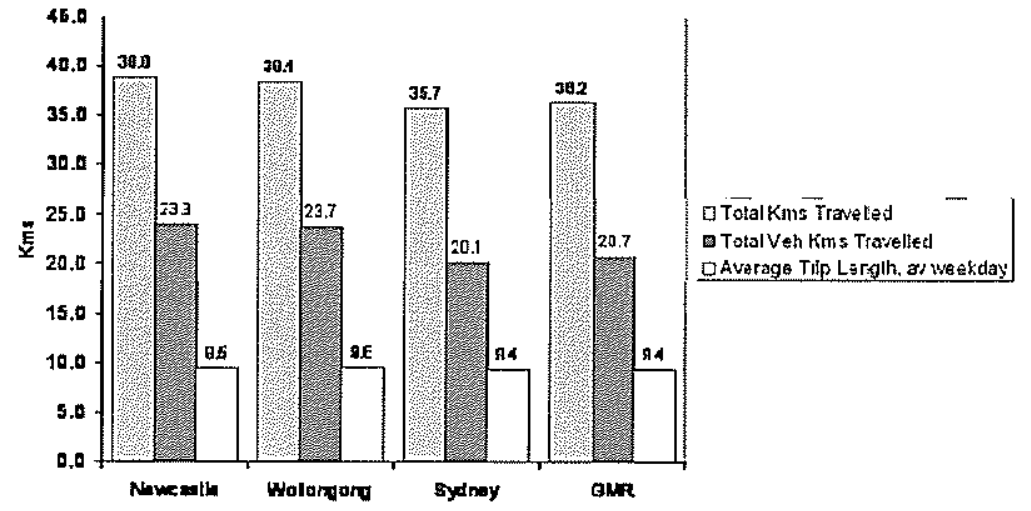

Source: NSW Department of Transport (2002). 
This reflects fewer car trips and greater use of public transport in Sydney. In addition, average trip lengths in Sydney are actually lower than in its neighbouring cities, despite the fact that it is much larger geographically. This reflects the tendency for higher densities to be associated with a greater number of opportunities in the local area, a higher quality public transport service, and higher levels of road congestion. Australian evidence suggests that density and public transport effects in our largest cities (particularly Sydney and to a lesser extent Melbourne) outweigh the physical size effect, meaning that from a transport fuel and greenhouse emissions perspective, the largest cities are in fact more sustainable than either the smaller capitals, or smaller regional cities.

At the sub-metropolitan level, there are marked differences within our cities in car use in petrol consumption and transport $\mathrm{CO}_{2}$ emissions. For example Dodson and Sipe (2006) showed that lower income outer suburban households are the most vulnerable to rising petrol prices. In the case of Sydney, analysis by the authors of travel zone-level data shows a predictable pattern of car-km per household, with the lowest values generally in the inner suburbs and in areas with the highest public transport access (close to good rail services, such as along the western rail line) and the highest values in the outer suburbs, particularly those suburbs furthest from the rail system (Figure 3 ). This highlights the effects of location, public transport access and local area density as found in other studies (for example Glazebrook, 2002 and Rickwood and Glazebrook, 2007).

Figure 3: Average Daily Household Car-Km in Sydney (1997-2004)

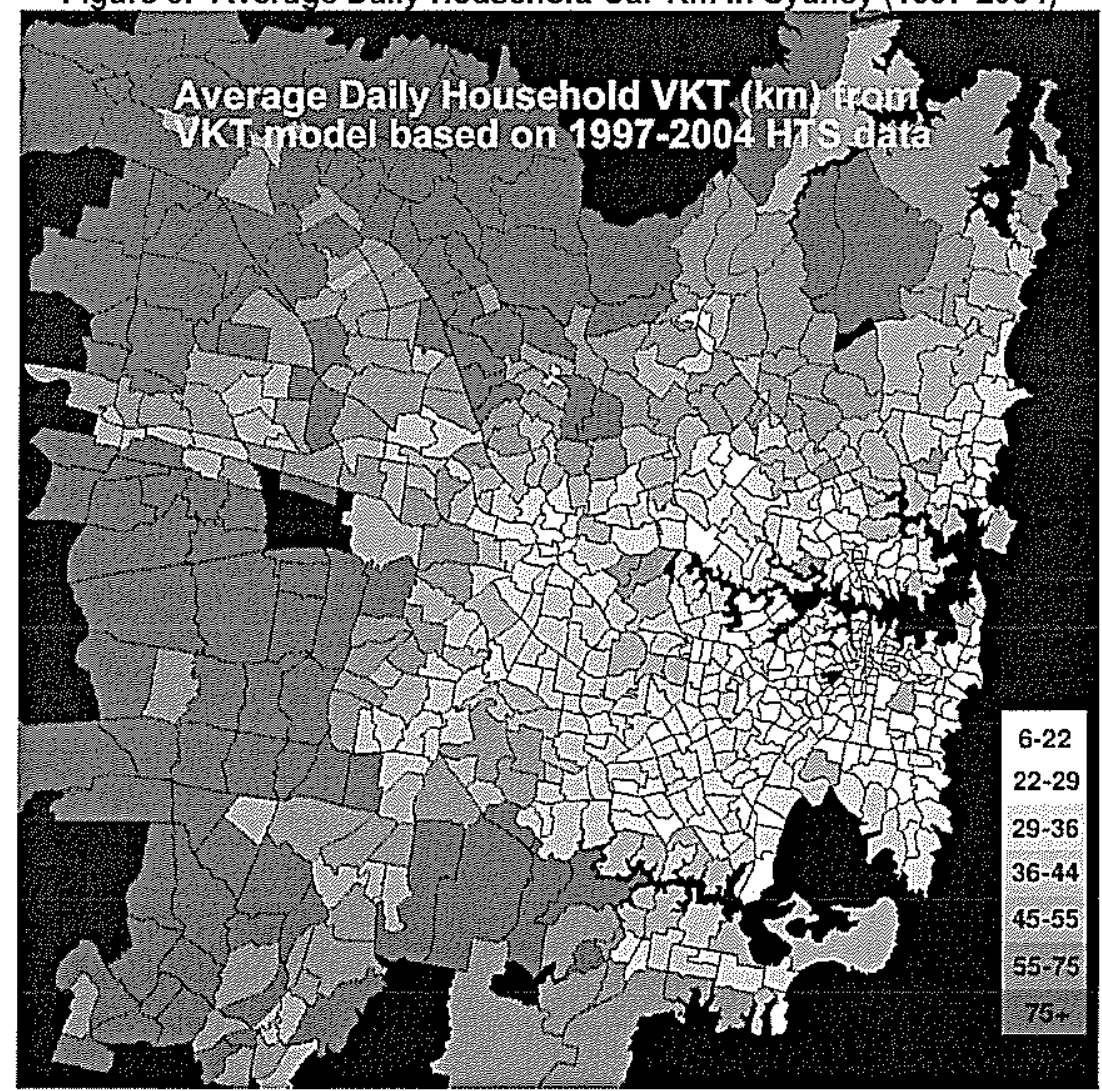

Source: Transport and Population Data Centre data analysed by Peter Rickwood, utilizing a modification of the model developed by Corpus, McCabe and Ryszawa (2006).

\section{$4 \quad$ Potential Mitigation Strategies}

There are a number of possible approaches for mitigating the effects of climate change and /or peak oil in relation to Sydney's urban transport, including reducing the overall amount of travel undertaken; reducing $\mathrm{CO}_{2}$ and oil intensity for specific transport modes; shifting travel towards more sustainable modes; and developing replacements for oil as a transport fuel. These are discussed briefly below.

\section{Reducing Overall Travel}

Over the last three decades to 2000 , Sydney's population grew by $37 \%$, but the number of trips grew by $142 \%$ (State Transport Study Group, 1974 and NSW Department of Planning, 2005). The number 
of trips per person grew strongly, reflecting such factors as increased car ownership, smaller households, greater affluence, increased female labourforce participation and lifestyle changes such as dining out. However more recent travel data for Sydney from the Household Travel Survey indicates that average trip lengths, trips per person, VKT per person and time spent travelling per person appear to have been almost constant in recent years, although car ownership continues to grow, and the mode share for vehicle driver trips continues to increase slowly at the expense of public transport (Table 4).

Table 4: Recent Trends in Travel in Sydney

\begin{tabular}{|l|c|c|c|c|c|c|}
\hline Year & 1999 & 2000 & 2001 & 2002 & 2003 & 2004 \\
\hline Trips per person (weekday) & 3.82 & 3.78 & 3.74 & 3.78 & 3.82 & 3.80 \\
Average Trip Length (km) & 9.3 & 9.5 & 9.5 & 9.4 & 9.3 & 9.3 \\
VKT per person (km) & 20.1 & 20.3 & 20.0 & 20.4 & 20.4 & 20.3 \\
Daily travel time per person (mins) & 79 & 79 & 79 & 79 & 79 & 79 \\
Vehicles per household & 1.40 & 1.41 & 1.41 & 1.45 & 1.46 & 1.49 \\
\hline$\%$ of kilometres by: & & & & & & \\
Vehicle Driver & $57.8 \%$ & $58.1 \%$ & $58.1 \%$ & $58.8 \%$ & $59.0 \%$ & $58.9 \%$ \\
Vehicle Passenger & $22.4 \%$ & $22.4 \%$ & $22.4 \%$ & $21.8 \%$ & $21.4 \%$ & $21.9 \%$ \\
Train & $10.5 \%$ & $10.2 \%$ & $10.2 \%$ & $10.0 \%$ & $10.2 \%$ & $9.8 \%$ \\
Bus & $4.8 \%$ & $4.8 \%$ & $4.7 \%$ & $4.6 \%$ & $4.3 \%$ & $4.3 \%$ \\
Walk & $3.1 \%$ & $3.0 \%$ & $3.0 \%$ & $3.2 \%$ & $3.2 \%$ & $3.3 \%$ \\
Other Modes & $1.3 \%$ & $1.3 \%$ & $1.6 \%$ & $1.7 \%$ & $1.8 \%$ & $1.8 \%$ \\
\hline
\end{tabular}

Source: NSW Department of Planning (2005) Tables 2.1 and 2.3

This relative stability in overall per-capita travel in Sydney may reflect the idea of the "travel time budget" (Newman, 2005). The sudden drop in the mode share for trains in 2004 lends further weight to this thesis as this coincided with a plunge in on-time running from $92 \%$ in 2003 to around $50 \%$ in February 2004. Both the time series data for Sydney, and comparative data with other cities, suggest that travel in Sydney is being constrained by travel time considerations.

As discussed below, options for reducing total per-capita travel include increasing the price of travel, land use changes, behaviour change programs and measures to restrain car use.

Changing the price of travel has an impact of travel behaviour. For example the sudden rise in petrol prices in Australia since early 2005 , from around $\$ 1.00$ per litre to as high as $\$ 1.40$ per litre, had a measurable impact on public transport patronage. For example patronage on Melbourne's trains has grown by $20 \%$ in the last two years (Metlink, 2007), while overall public transport patronage in SouthEast Queensland has grown by $30 \%$ since July 2004 (Translink, 2007). Similarly the introduction of tolls on the Cross-City Tunnel and the Lane Cove Tunnel in Sydney following the initial toll-free period was followed by an immediate drop of around 30\% in traffic volumes. Congestion charging in cities like Singapore, London and Stockholm has also proved effective in reducing travel (by car). For example Beevers and Carslaw (2005) found a 15\% reduction in veh-km in the London Charging Zone following introduction of the congestion charge, and a $12 \%$ reduction in NOx and PM10 poilution. Notwithstanding recent price increases, petrol and diesel prices in Australia are amongst the lowest in the world, and well below prices in Europe, Japan and most other developed economies, reflecting the relatively low fuel taxes in this country. Petrol is important in terms of driver behaviour, as it makes up a significant part of the "out-of-pocket" costs perceived by motorists when making individual trips (Glazebrook, 2007).

There are complex relationships between land use patterns and travel (Ewing et al., 2001). Specific land use changes which could potentially reduce travel in Sydney include urban consolidation, and achieving a better jobs-population balance by increasing the number of jobs in Western Sydney. As shown in Figure 3 households in outer suburbs of Sydney (>40km from the CBD) typically generate more than $55 \mathrm{~km}$ per day of car travel, and in many cases over $75 \mathrm{~km}$ per day, whereas households in the inner suburbs typically generate less than $30 \mathrm{~km}$ of driving per day. Clearly even allowing for an effect of self-selection, urban consolidation policies will be favourable from a fuel use and transport $\mathrm{CO}_{2}$ perspective.

Improving jobs-labourforce balance has been identified in the US as a way to reduce car-kms for commuting (Cervero and Duncan, 2006). However the situation elsewhere may be complex, as shown by Filion (2001) for Toronto, or by the experience of Canberra which has the highest per capita transport energy consumption despite a plan based on separate towns each with their own centre. In 
the case of Sydney, any reduction in the proportion of metropolitan jobs which are located in the CBD is likely to prove counter-productive from a petrol and greenhouse perspective given that public transport modes shares for CBD jobs are in excess of $70 \%$, much higher than to other locations, where they are generally $10-20 \%$. Thus job locations with low total energy costs (including both public and private transport) included the CBD, North Sydney and many inner suburbs; by contrast, white collar jobs located in outer suburbs like Liverpool, Blacktown, Penrith and Baulkham Hills generate high energy costs (Figure 4). Hence the focus for decentralisation of white collar jobs should be to create a small number of secondary CBD's (like Parramatta) which can have their own strong transit networks.

Figure 4: Total Energy Cost per White Collar Employee by Job Location LGA in Sydney

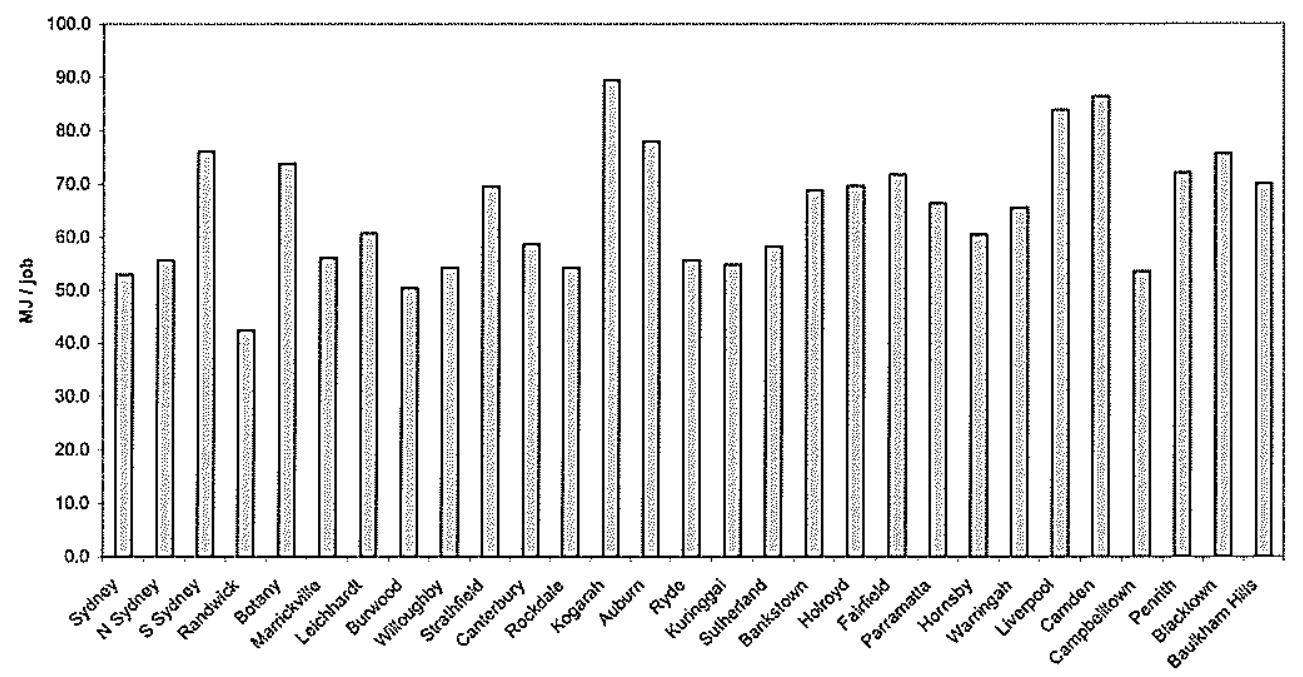

L.GA

Source: Glazebrook (2002)

Pilot behaviour-change programs such as Travel Smart are claimed to be able to significantly reduce car travel and to shift some trips to walk/cycle/public transport (Ampt and Rooney, 1999, Taniguchi et al., 2003). If these results are able to be extrapolated at a large scale, they would have a significant overall impact. However it is also not clear whether the results in cities like Perth and Adelaide are replicable in Sydney, where there are few cycling facilities and public transport currently faces capacity constraints, unless these issues are addressed (see later discussion).

Probably the surest way to reduce overall travel is to restrict car travel by measures such as parking prices / availability, congestion charges or traffic management. The difficulties here are not technical but rather political, as illustrated by the reaction to lane closures planned as part of the Cross-City Tunnel and Lane Cove Tunnel projects. Nevertheless a growing number of cities are pedestrianizing city centres (eg Copenhagen, Strasbourg, and many other cities in Europe, Japan and elsewhere).

\section{Reducing $\mathrm{CO} 2$ and Oil intensity of urban transport modes}

For cars, options to reduce petrol/oil consumption and potentially GHG emissions include use of ethanol or other biofuels, shifts to smaller, more fuel-efficient vehicles (such as hybrids) and shifts to all-electric vehicles. Ethanol is already being sold in Australia in blends with petrol up to $10 \%$, and biodiesel has been tested and successfully used in varying blends. These options can certainly reduce $\mathrm{CO}_{2}$ and oil intensity of urban transport $\mathrm{CO}_{2}$. However there are some limits on the extent to which such options can be applied in Australia, and indeed more widely, unless cellulosic based production can be made viable (Bezdek, 2007).

Currently available hybrid cars (usually petrol-electric) such as the Toyota Prius are claimed to achieve fuel savings of $50 \%$ or more compared with current vehicles. However, much of the fuel savings attributed to hybrid cars are due to their relatively small size and weight. For example the Prius is only around $30 \%$ more fuel-efficient than equivalent size cars. Similarly diesel-engined vehicles are around $20 \%$ more fuel efficient than similar sized gasoline-engine powered cars. All-electric cars (or "plug-in" electric, powered by batteries recharged from mains electricity) could dramatically reduce oil consumption, but the impact on greenhouse gas emissions will depend on the source of electricity; if 
sourced from coal, their greenhouse emissions could be worse than current cars. In all cases, a limiting factor in the ability of changes in fuel or vehicle technology for cars to be effective is the time to gear up the industry for producing the new vehicles and infrastructure, and the time taken to achieve $100 \%$ penetration of the vehicle fleet; full benefits are therefore likely to take at least 30 years to achieve.

Current energy consumption for urban train operations in Sydney is approximately $500 \mathrm{GWHr}$, with additional power used for station lighting, maintenance facilities etc. Power is presently purchased commercially and is therefore approximately $90 \%$ sourced from black coal, with the remainder mostly hydro-electric power and gas, plus a very small component from wind-power. A number of options for improving the energy efficiency of Cityrail have been identified by CityRail, including use of 4-car sets off-peak, turning off air conditioning systems and lighting when vehicles are stored between services, and greater use of regenerative braking (Halcrow, 2006). Estimates by the authors indicate that Cityrail could convert to $100 \%$ green-power over the next three years for its train operations for an annual premium of a little over $1 \%$ of Cityrail's budget, based on current premiums charged for greenpower; the power requirements could be met with a modest enhancement of wind-power.

Finally we consider buses, which in Sydney account for some $4.3 \%$ of weekday passenger travel and are powered almost exclusively by diesel or CNG. Options for improving the primary energy efficiency of buses are limited, and should probably focus more on efficient infrastructure and operating conditions than on vehicle-based improvements. However oil-dependence and $\mathrm{CO}_{2}$ could be reduced by using biodiesel, switching to $\mathrm{CNG}$, introducing hybrid electric buses, or replacing buses by light rail.

\section{Shifting Travel to More Sustainable Modes}

Urban public transport uses $65 \%$ less primary energy per passenger-kilometre in Sydney than cars (Glazebrook 2002), while walking and cycling use virtually no energy. As has been widely reported, the share of trips by car in Sydney has increased at the expense of the more energy and greenhouse efficient modes. Under these circumstances, it is legitimate to ask whether it is feasible to at least halt this trend if not reverse it in future. More detailed analysis of travel patterns in Sydney shows a slightly more complex picture within the broad trend noted above. In particular:

- After declining in absolute terms during the 1970's and early 1980's, patronage on Cityrail rebounded, growing nearly $40 \%$ by 2000 . Since then it has been relatively static, as a result of declining reliability, cuts in services and the $5 \%$ cut in average speeds introduced in the 2005 timetable. Patronage has in fact risen slightly in the last two years but is constrained by lack of rollingstock.

- Bus patronage in Sydney has fallen generally in the post war period, but has now bottomed out, with some growth recently following some new investments and areas of growth, such as the transitways in Western Sydney. However patronage gains have been limited by the failure to increase overall bus numbers and by cuts to less well-patronised services.

While current peak capacity is constrained by rollingstock availability, infrastructure capacity is being increased by the addition of the NW busway (opened in 2007); additional cross-regional bus routes and bus priority projects; the Epping-Chatswood line (2008) and the rail clearways project (to be completed by 2012). These projects will boost Sydney's public transport capacity by $25 \%$. In addition the State Government has announced plans to build the SW rail line by 2012, the NW rail line by 2017 , and the second harbour crossing by 2017 ; these projects will add a further $25 \%$ to peak rail capacity. Most recently, the Government has indicated it is investigating additional rail infrastructure in the form of metro lines (similar to London Underground), a number of which have been identified in earlier reports (Christie, 2001).

Thus Sydney's total public transport network could have its peak capacity and patronage doubled within 30 years with suitable investment, while off-peak patronage could be increased considerably more than this. The ability to achieve this will depend, however, not only on the necessary investments but also on supportive policies to encourage a switch from private to public transport. In this context the essential problem with urban transport is that the "out of pocket" costs for using a car are only one-sixth of the full social costs (including externalities); as a result, the sum of individual "rational" choices is a far from rational for society as a whole (Glazebrook, 2007).

\section{Substituting Gas, Unconventional Oil or Coal for Oil}

Although liquefied petroleum gas (LPG) is already used for most taxis and certain other high mileage fleets it is questionable whether large scale use of natural gas for vehicle fleets is feasible at prices which are competitive with petrol or diesel, unless favourable tax treatment is given. In any event 
natural gas is also expected to reach peak production world wide not long after oil, and has already peaked in the United States.

Unfortunately while unconventional oil (tar sands, shale oil, polar oil, deep water oil) and coal-to-liquids can extend oil reserves, these will not only involve high capital and environmental costs, but also produce higher greenhouse gas emissions per unit of final energy than conventional oil. Assuming some form of carbon tax or equivalent is applied within the next few years, all of these options are likely to be more expensive than current oil, and may even not be pursued because of over-riding concerns at global warming.

\section{$5 \quad$ Future Scenarios}

Given the uncertainties surrounding both future climate change and the time when global oil production peaks, three potential scenarios have been developed for assessing alternative strategies (Table 5). These are based on analysis by the authors of possible trends in the oil and climate change situation.

Table 5: Potential Climate Change and Peak Oil Scenarios

\begin{tabular}{|l|c|c|c|c|}
\hline Scenario & & Scenario A & Scenario B & Scenario C \\
\cline { 2 - 5 } & & Optimistic & $\begin{array}{c}\text { Current } \\
\text { Expectation }\end{array}$ & Pessimistic \\
\hline Date for Global Carbon Trading / Taxation Regime & & 2015 & 2012 & 2010 \\
\hline Target reduction in global $\mathrm{CO}_{2}$ emissions by & 2020 & $10 \%$ & $20 \%$ & $30 \%$ \\
& 2050 & $30 \%$ & $50 \%$ & $90 \%$ \\
\hline Carbon "Price US2007 \$/ tonne $\mathrm{CO}_{2}$ & 2020 & $\$ 20$ & $\$ 60$ & $\$ 100$ \\
& 2050 & $\$ 40$ & $\$ 100$ & $\$ 150$ \\
\hline Timing for Peak Oil & & 2025 & 2015 & 2005 \\
\hline Target reduction in transport oil use per capita by & 2020 & $10 \%$ & $20 \%$ & $40 \%$ \\
& 2050 & $30 \%$ & $40 \%$ & $60 \%$ \\
\hline Oil Price (US2007 \$/barrel) & 2007 & $\$ 70$ & $\$ 70$ & $\$ 70$ \\
& 2020 & $\$ 80$ & $\$ 120$ & $\$ 200$ \\
\hline
\end{tabular}

Source: Authors

Scenario $A$, representing an optimistic outlook, assumes that scientists have over-estimated the impact of global warming and/or that carbon sequestration is successfully developed, and that global oil production can continue to increase for the next twenty years before peaking. This scenario would fit with relatively low carbon and oil prices and provide maximum adjustment time.

Scenario $B$ represents current expectations; in particular that global $\mathrm{CO}_{2}$ emissions will need to be reduced by at least $20 \%$ by 2020 and $50 \%$ by 2050 , and that peaking of oil production is relatively close (2015). Accordingly carbon prices are assumed to be of the order of US\$60/tonne $\mathrm{CO}_{2}$ by 2020 , while oil prices could also be expected to rise rapidly to force oil consumption to match supply.

Scenario $C$ represents a pessimistic scenario, in which peak oil has already occurred, with consequent very significant rises in oil prices so that a supply-demand balance is reached. In addition, this scenario assumes that climate change emerges even more forcefully than in the IPCC forecasts, for example because of rapid ice-sheet deterioration in Greenland and Antarctica, threatening low lying areas of the world with inundation. In this scenario very high carbon prices could be expected.

In all scenarios, it is likely that any carbon trading / taxing scheme will be extended to cover mobile energy users, even though the impact of carbon taxes on urban transport is likely to be modest (Bruvoll and Larsen, 2004). More importantly, under Scenario $\mathrm{C}$ and possibly Scenario B it is likely that remaining oil and gas reserves will increasingly be husbanded for the most important uses, such as fertiliser and plastics production and for powering road freight vehicles, for which substitutes are difficult. This would leave much less petrol and diesel available for use in private automobiles. We have already seen how the future might unfold, for example in Iran and Indonesia where rising petrol/ kerosene prices and rationing have caused social unrest. Despite being a net energy exporter (coal and LNG), Australia already has large oil imports ( $\$ 9$ billion in 2005/6) and will not want to forego export revenue potential from any further development of its oil or gas reserves. Consequently Australians will have to pay world prices for oil and gas. 
6 Discussion: Implications for Sydney's Transport

Figure 5 shows the implications for petrol prices in Sydney under the three scenarios, measured in today's dollars, and assuming no change is made to the current petrol tax regime. Under Scenario $A$, petrol would be likely to increase somewhat in real terms, but at a rate which could be countered by improving vehicle efficiency. Under scenario $B$, real prices would more than double by 2050 , implying significant pressure to reduce total travel demand, shift to other modes, and make other adjustments. Substantial economic impacts would also be likely. Under Scenario C, prices per litre of conventional petrol would more than double within 13 years, and more than triple longer term, implying very significant changes in our cities and transport patterns, and very substantial economic impacts.

Figure 5: Estimated price of Petrol in Current $\$ /$ litre under Different Scenarios

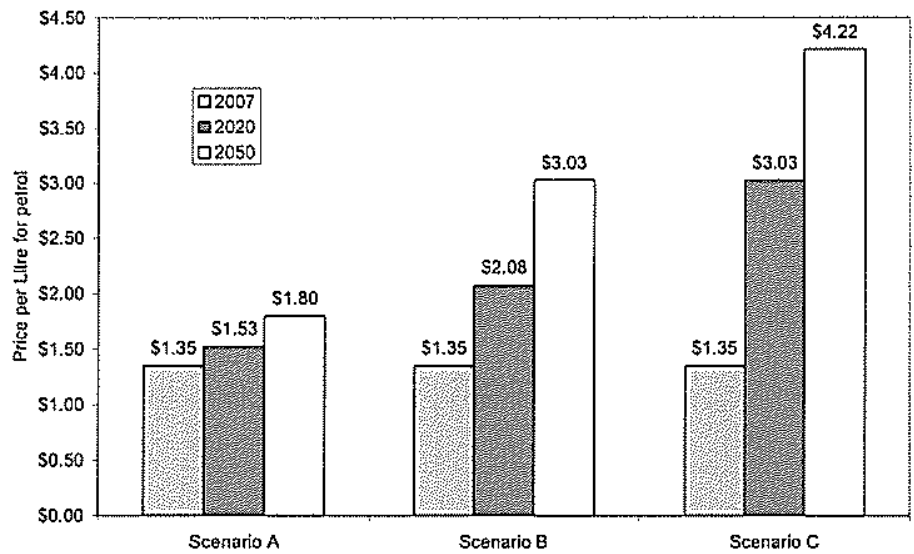

Source: Authors

Accordingly it can be expected that even under Scenario $A$ there will be pressure on cities in the near future to reduce urban transport oil consumption and greenhouse emissions. No city can be assumed to be exempt from such pressure. How much could we achieve in Sydney? Table 6 sets out some broad estimates of what might be possible in different timescales, based on the earlier discussion.

Table 6: Potential Contributions from Different Strategies

\begin{tabular}{|c|c|c|c|c|c|c|c|}
\hline \multirow[t]{2}{*}{ Strategy } & \multirow[t]{2}{*}{ Measure } & \multirow[t]{2}{*}{ Note } & \multirow[t]{2}{*}{ Scenario } & \multicolumn{2}{|r|}{ Use } & $\mathrm{CO} 2$ & Emissions \\
\hline & & & & 2020 & 2050 & 2020 & 2050 \\
\hline \multirow[t]{5}{*}{ Reduce Travel } & Fuel Price & 1 & A & $-3 \%$ & $.7 \%$ & $-3 \%$ & $-7 \%$ \\
\hline & & & B & $-11 \%$ & $-25 \%$ & $-11 \%$ & $-25 \%$ \\
\hline & & & C & $-25 \%$ & $-42 \%$ & $-25 \%$ & $-42 \%$ \\
\hline & Land Use & 2 & & $-8 \%$ & $-16 \%$ & $-8 \%$ & $-16 \%$ \\
\hline & Travel Demand Measures & 3 & & $-10 \%$ & $-10 \%$ & $-10 \%$ & $-10 \%$ \\
\hline \multirow[t]{4}{*}{ Fuel/Energy } & $10 \%$ Ethanol for cars & 4 & & $-10 \%$ & $-10 \%$ & $-10 \%$ & $-10 \%$ \\
\hline & Fleet Economy & 5 & & $-9 \%$ & $-30 \%$ & $-9 \%$ & $-30 \%$ \\
\hline & Rail Greenpower & 6 & & $0 \%$ & $0 \%$ & $-5 \%$ & $-5 \%$ \\
\hline & Biodiesel for buses & 7 & & $-1 \%$ & $-2 \%$ & $-1 \%$ & $-2 \%$ \\
\hline \multirow[t]{2}{*}{ Shifting Modes } & Walk/cycle & 8 & & $-1 \%$ & $-3 \%$ & $-1 \%$ & $-3 \%$ \\
\hline & Public Transport & 9 & & $-9 \%$ & $-18 \%$ & $-9 \%$ & $-18 \%$ \\
\hline
\end{tabular}

1 Assumes long-term petrol price elasticity of $-20 \%$

2 Assumes $80 \%$ of future population growth in areas with high or very high Public Transport accessibility

3 Assumes Road and P Transport pricing reduces overall travel by $10 \%$ by 2050

4 Assumes introduced by 2020 for all cars

5 Assumes all new vehicles sold after 2012 are $30 \%$ more energy efficient

6 Assumes this is implemented by 2012

7 Assumes $30 \%$ of buses use biodiesel by $2020,100 \%$ by 2050

8 Assumes walk/cycle is $6 \%$ of travel (pass-kms) by $202,9 \%$ by 2050

9 Assumes Public Transport carries $17 \%$ of annual pass-km by $2020,25 \%$ by 2050 . 
These are based on estimating the reductions in Oil and $\mathrm{CO} 2$ emissions compared with business as usual as explained in the footnotes to the table. At first glance, this looks promising, and it would appear that there are many choices available. However Sydney is expected to continue growing, while many of the above effects will overlap - for example, the reductions expected from very high petrol prices in Scenario $\mathrm{C}$ would involve reduced travel, mode shifts, land use changes, radical improvements in fuel economy and shifts to other fuels.

To analyse this further, Figure 6 shows the combined effects of a multi-pronged approach and compares this with the likely outcome from population growth but with business as usual assumptions (constant travel per capita, no improvements in efficiency, and a slow move away from sustainable modes). The multi-pronged approach involves $10 \%$ travel demand reduction (eg travel smart programs etc); $30 \%$ increase in private vehicle energy efficiency plus $20 \%$ replacement of petrol by bio-fuels or electricity based on greenpower; $100 \%$ greenpower for rail and $100 \%$ biodiesel for buses; and a doubling of the current shares for walking/cycling and public transport measured in pass-km.

Figure 6: Impact of Combined Strategies Compared with Business as Usual

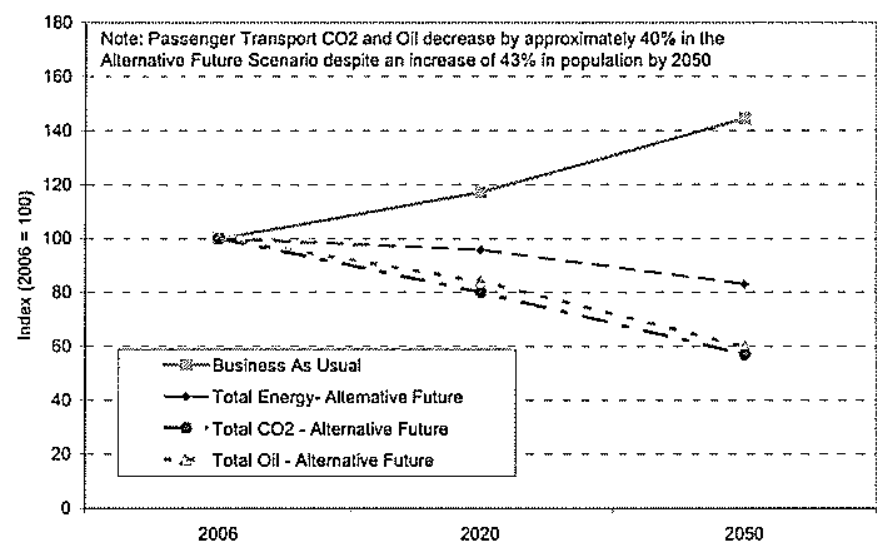

Source: Authors calculations

The methodology used was to estimate total passenger-km for future years, then break it into different mode shares, and apply specific energy, fuel and $\mathrm{CO}_{2}$ emission parameters, based on the specific assumptions for each scenario. As can be seen, a combination of all available strategies is likely to be necessary to make substantial inroads into transport - related greenhouse and oil consumption in a growing city. Business as usual is highly unlikely to be acceptable under any future scenario.

\section{Conclusion}

As we enter the $21^{\text {st }}$ century, the world faces significant challenges from global warming and peak oil; their synchronicity is likely to reduce the scope for avoiding one or the other. No country, industry or city is likely to be able to ignore this challenge, and contributions to global solutions are likely to be required across the board. Urban transport in Sydney is no exception. Analysis of potential scenarios and strategies suggest a multi-pronged approach using all available policy levers will be necessary. Failure to begin the transitions required will run a substantial risk of sudden adjustments being forced on the city and its inhabitants via high oil prices and possible oil shortages. Fortunately, Sydney is relatively well-endowed with public transport in comparison with other Australian (and US) cities, and with the plans already underway has a real chance of avoiding major disruption. But as with climate change, the faster we adjust now to the threat of peak oil, the lower will be the ultimate costs.

\section{References}

Ampt, E. and Rooney, A. (1999): "Reducing the Impact of the Car - A Sustainable Approach: Travel Smart Adelaide". Australasian Transport Research Forum, Perth, September 29 - October $1^{\text {st }}$.

Beevers, S. and Carslaw, D. (2005): "The Impact of Congestion Charging on Vehicle Emissions in London". J. Atmospheric Environment. V39 No 1, pp 1-5.

Bezdek, R. (2007):" Looming Oil Problems: Myths and Realities". Keynote speech at Smart 2007 Conference, Sydney, June 2007. Accessible via http://globalpublicmedia.com/roger_bezdek_sydney_smart_conference_keynote_address

Bruvoll, A. and Larsen, B. (2004): "Greenhouse gas emissions in Norway: do carbon taxes work?" Energy Policy. Volume 32, issue 4, p493-505. 
Cervero, R. and Duncan, M. (2006): "Which Reduces Vehicle Travel More: Jobs-Housing Balance or Retail-Housing Mix?". J. American Planning Association. Autumn 2006, 72, 4, 475-490.

Christie, R. (2001): "Long-Term Strategic Plan for Rail: Greater Sydney Metropolitan Region. Overview Report". Office of Coordinator-General of Rail. Report released to NSW Legislative Council in May 2002.

Corpuz, G., McCabe, M. and Ryszawa, K. (2006): "The Development of a Sydney VKT Regression Model". $29^{\text {th }}$ Australian Transport Research Forum. Gold Coast.

Dodson, J. and Sipe, N. (2006): "Shocking the Suburbs: Urban Location, Housing Debt and Oil Vulnerability in the Australian City". Griffith University Urban Research Program, Research Paper No 8, July 2006.

Dunlop, I. (2007): "Peak Oil and Values for 21C". Towards 2020 Climate Change Conference, Sunshine Coast, Qld, 8-9 June 2007.

Ewing, R., Cervero, R., Nelson, D., and Niles, J. (2001): "Travel and the Built Environment: A Synthesis. Discussion". Transportation Research Record. No 1780, pp87-114.

Filion, P. (2001): "Suburban mixed-use centres and urban dispersion: what difference do they make?" Environment and Planning A 2001, volume 33, 141-160.

Glazebrook, G. (2002): "Transport and Energy Use in Sydney". University of Sydney Warren Centre Report on "Sustainable Transport for Sustainable Cities", Sydney, 2002.

Glazebrook, G. (2007): "Taking the Con out of Convenience: The True Cost of Travel Modes in Sydney". Urban Policy and Research. (Submitted for publication).

Halcrow (2006): "A Report on Rail Initiatives for Reducing Energy Demand". Report prepared for State Rail. October 2006.

Hansen, J. and 46 co-authors (2007): "Dangerous human-made interference with climate: a GISS Model E study". Atmos. Chem. Phys., 7, 2287-2312. PDF available at http://pubs.giss.nasa.gov/abstracts/2007/Hansen etal.1.html.

Hirsh, R., Bezdek, R. and Wendling, R. (2005): "Peaking of World Oil Production: Impacts, Mitigation and Risk Management". Energy Bulletin, 19 March 2005. Accessible at http://www.energybulletin.net/4789.html

H.M. Treasury (2006): "The Stern Review on the Economics of Climate Change". http://www.hmtreasury.gov.uk/independent_reviews/stern_review_economics_climate_change/stern_review report.cfm

International Energy Agency (2005): "Saving Oil in a Hurry: Measures for Rapid Demand Restraint in Transport". Review Draft. 28 February 2005.

IPCC (2007): "Climate Change 2007: The Physical Basis - Summary for Policymakers" (http://www.jpcc.ch/SPM2feb07.pdf)

Metlink (2007): "Melbourne's metro trains and trams to be tendered". 21 August 2007. www.metrolinkmelbourne.com.au/news/media releases/metropolitan general/melbournes metro trains and trams to be tendered.

Newman, P. (2005): "Sustainability and Cities: The Business Case for Rail". Submission to the House of Representatives Committee Inquiry into Sustainable Urban Transport, April 28, 2005.

Newman, P. and Kenworthy, J. (1999): "Sustainability and Cities: Overcoming Automobile Dependence". Island Press. Washington.

NSW Government (2007): Transport Infrastructure Statement.

NSW Department of Transport (2002): "Travel in Newcastle and Wollongong". Issues paper 2002/01. February 2002.

NSW Department of Planning (2005): "2003 Household Travel Survey Summary Report: 2005 Release". Transport and Population Data Centre.

Rickwood, P. and Glazebrook, G. (2007): "Urban Structure and Commuting in Australian Cities". State of Australian Cities Conference, Adelaide, December 2007 (submitted).

Rutledge, I. (2005): “Addicted to Oil: America's Relentless Drive for Energy Security". Taurus, London.

Simmons, M. (2005): "Twilight in the Desert: The Coming Saudi Oil Shock and the World Economy". John Wiley and Sons, New Jersey.

Simmons, M. (2007): "Sunrise in Coal Fields: Coal's Role in a Peak Oil World". Presentation to Peabody Energy, March $3^{\text {rd }}, 2007$, Colorado.

Standing Committee on Rural and Regional Affairs and Transport (2007): "Australian's future oil supply and alternative transport fuels. Final Report". Feb. 2007. Australian Senate, Canberra.

State Transport Study Group (1974): "SATS V2: Travel Model Development and Forecasts".

Taniguchi, A., Hara, F., Takano, S., Kagaya, S. and Fujii, S. (2003): "Psychological and Behavioural Effects of Travel Feedback Program". TRB 2003 Annual Meeting. Accessed via http://www.Itrc.Isu.edu/TRB 82/TRB2003-001711.pdf

Translink (2007): "Translink Network Plan 2004-5 to 2007-8. Factsheet 07". www.translink.qld.gov.au/9f/translink.nsf/Referencelookup/np_factsheet_07.pdf. 